\title{
Emerging Trends in Automotive Lightweighting through Novel Composite Materials
}

\author{
Muhammad Pervaiz1 ${ }^{*}$, Suhara Panthapulakkal1, Birat KC1, Mohini Sain 1,2, Jimi Tjong1,3,4 \\ ${ }^{1}$ Center for Biocomposites and Biomaterials Processing, Faculty of Forestry, University of Toronto, Toronto, \\ Canada \\ ${ }^{2}$ Center of Excellence for Advanced Materials Research, King Abdulaziz University, Jeddah, KSA \\ ${ }^{3}$ Faculty of Forestry, University of Toronto, Toronto, Canada \\ ${ }^{4}$ Powertrain Engineering Research and Development Centre, Ford PERDC Engineering, Windsor, Canada \\ Email: *muhammad.pervaiz@utoronto.ca
}

Received 22 December 2015; accepted 26 January 2016; published 29 January 2016

Copyright (C) 2016 by authors and Scientific Research Publishing Inc.

This work is licensed under the Creative Commons Attribution International License (CC BY).

http://creativecommons.org/licenses/by/4.0/

\section{(c) (7) Open Access}

\section{Abstract}

Owing to unprecedented climate change issues in recent times, global automotive industry is striving hard in developing novel functional materials to improve vehicle's fuel efficiency. It is believed that more than a quarter of all combined greenhouse gas emissions (GHG) are associated with road transport vehicles. All these facts in association with heightened consumer awareness and energy security issues have led to automotive lightweighting as a major research theme across the globe. Almost all North American and European original equipment manufacturers (OEMs) related to automotive industry have chalked out ambitious weight reduction plans in response to stricter environmental regulations. This review entails main motives and current legislation which has prompted major OEMs to have drastic measures in bringing down vehicle weight to suggested limits. Also discussed are recent advances in developing advanced composites, and cellulose-enabled light weight automotive composites with special focus on research efforts of Center for Biocomposites and Biomaterials Processing (CBBP), University of Toronto, Canada.

\section{Keywords}

Automotive Lightweighting, Biocomposite, Cellulose, Hybrid Structures

\footnotetext{
*Corresponding author.
} 


\section{Introduction}

Automotive industry has always played a pivotal role to generate high-value and high-volume economic activity in almost all industrialized regions of world, especially in North America. It is reported that USA's automotive industry supports around seven million jobs worth $\$ 500$ billion in annual employee compensation; these private sector jobs include whole supply chain of suppliers, manufacturers and dealers [1].

Recent environmental issues related to global climate change and greenhouse gas emissions have prompted automotive manufacturers to focus on the development of lightweight and fuel efficient vehicles. The Greenhouse Gas emissions (GHG) associated with road transport vehicles account for $27 \%$ of all combined emissions in USA which translates into 1800 million metric tons of $\mathrm{CO}_{2}$ equivalent [2]. Globally, a very alarming trend of increase in $\mathrm{CO}_{2}$ emissions has been observed since 1980s, as shown in Figure 1, and since 95\% of the world's transportation energy is derived from fossil fuels [3], mostly diesel and gasoline, there arises an urgent need to curb transport related emissions to meet international environmental control obligations.

The above mentioned facts and consumer awareness have forced governments and environmental protection agencies to enforce stricter regulations in curbing the emissions which are directly responsible for drastic climate change phenomena around the world. Obama administration's recent commitment in November 2014 of an “Ambitious 2025 Target to Cut U.S. Climate Pollution by 26 - 28 Percent from 2005 Levels” [4] seems in direct response to global community's concern in combating rising $\mathrm{CO}_{2}$ emissions in last three decades. Achieving these emission cuts necessitates stringent fuel efficiency standards for automobiles which have forced OEMs worldwide to further reduce their vehicles' weight.

National Highway Traffic Safety Administration (NHTSA), USA, in association with Environmental Protection Agency (EPA), USA has jointly proposed a national program that would significantly reduce carbon emissions and improve the fuel efficiency of heavy-duty vehicles. This new initiative is intended to promote specific measures within automotive industry in reducing fuel consumption leading to significant savings of about 1 billion tons of GHG emissions. Lightweighting could be one major component to achieve these standards under which the fleet-wide fuel consumption is foreseen to drop as much $16 \%$ to $24 \%$, Figure 2 [5].

Apart from climate change and GHG emissions, other strategic and geopolitical concerns have also led to fuel saving measures in automotives, especially in USA. U.S. Department of Energy's Vehicle Technologies Office (VTO) programs have multidimensional mandate to develop automotive Lightweight Materials (LM) ensuring energy security through use of renewable sources [7]. Now it's a common understanding that a 10\% reduction in vehicle weight has potential to save $6 \%$ - 8\% fuel consumption [8] [9], and since lighter object needs less energy to get accelerated compared to heavy ones, obviously, lightweight materials provide a better opportunity to enhance vehicle's fuel economy and mitigate GHG emissions.

Traditionally, a car is made of a variety of materials ranging from glass and metals to plastic composites, Figure 3. As evident from data, metals make a significant part of whole vehicle weight; therefore, research efforts are underway to develop new advanced high strength steels (AHSS) to reduce the vehicle weight [11]. The

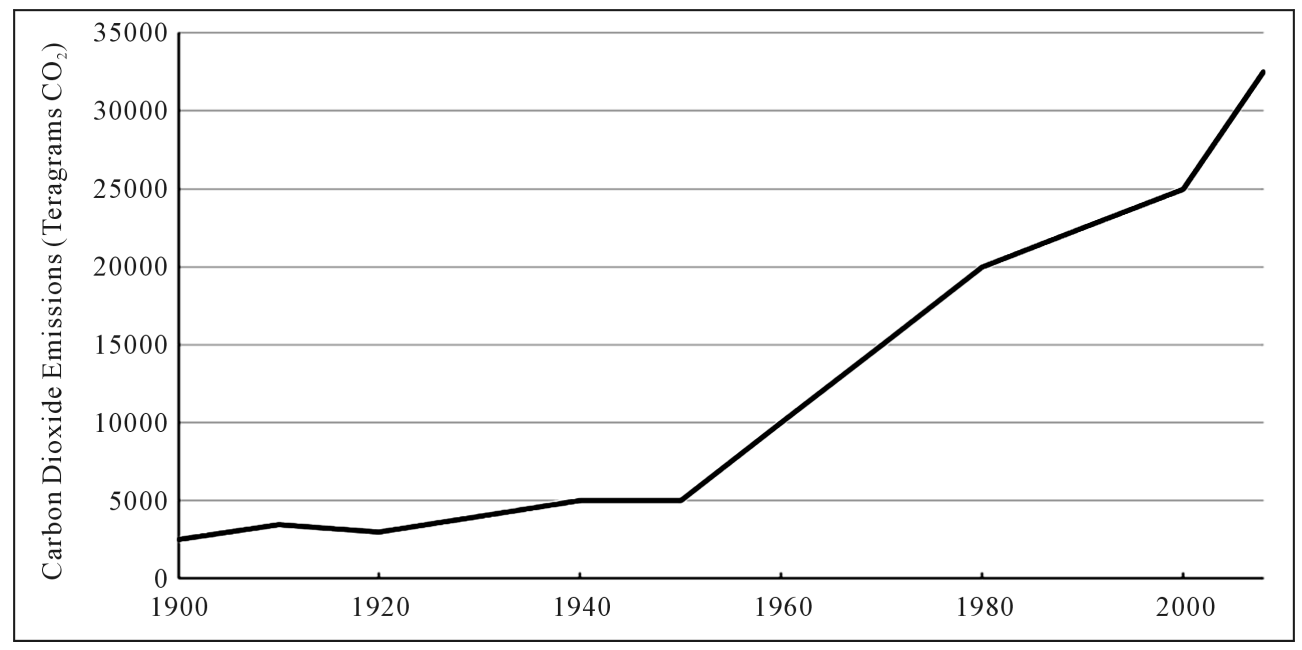

Figure 1. Global carbon dioxide $\left(\mathrm{CO}_{2}\right)$ emissions from fossil-fuels 1900-2008; data source [3]. 


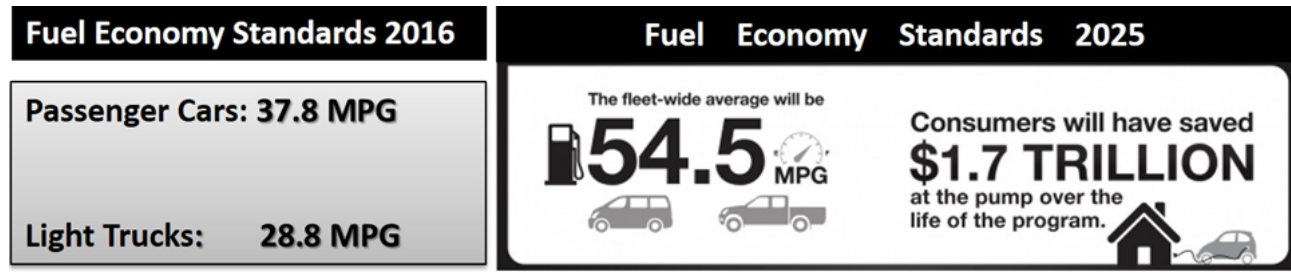

Figure 2. Current and projected trends of fuel efficiency standards in USA; data source [5] [6].

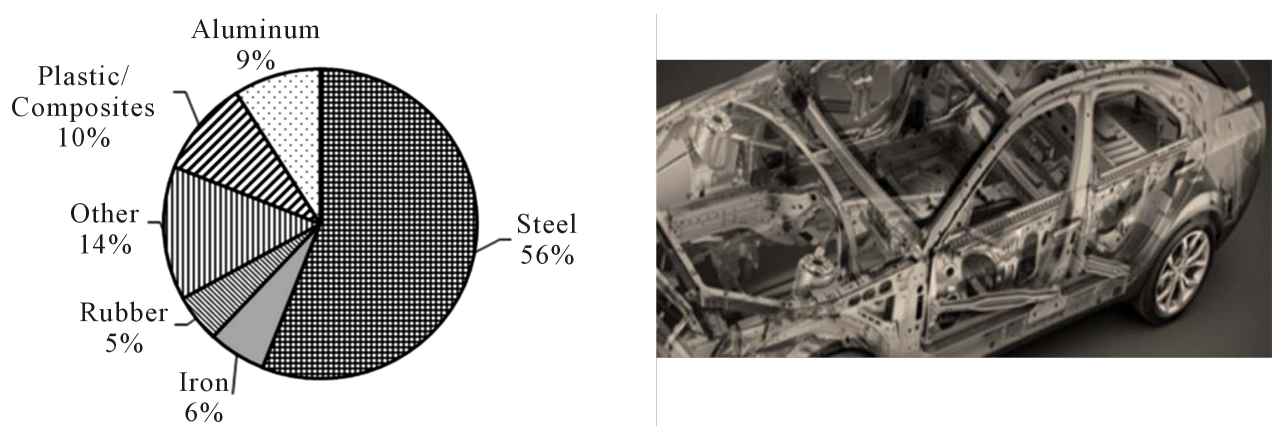

Figure 3. Material distribution of a standard vehicle; data source [10].

main thrust in this research area is to enable engineers in making informed decisions on material selection to have cost-effective weight reduction by substituting steels and AHSS in body and chassis structures of vehicles. A number of multinational companies are engaged in developing commercial products in this area; however, being metal in nature, there is certainly a limit up to which weight reduction can be achieved by employing the new class of steels and sheets. On the other hand, aluminium and magnesium and magnesium alloys have been also emerging as an alternative to steel for lightweighting; however, the use of these alternatives offsets the advantages of lightweighting with their high cost, performance and environmental impact.

Recent advances in polymers and novel composites have enabled these materials to be at the forefront of lightweight technologies. Since advance composites are of high strength and their rigidity also helps to maintain same or higher level of safety as provided by conventionally used materials to manufacture both aerospace and road transport vehicles. The primary advantages of using composites in automotives is the weight reduction as the composites are up to 35\% lighter than aluminium and 60\% lighter than steel and the use of composites in automotives can leads to an overall vehicle weight reduction of up to $10 \%$ [12]. In addition to this, tooling investments can be reduced up to $50 \%-70 \%$, as in one assembly, composites can replace eight metal stampings and hence have a positive impact on the energy associated with the assembly and tooling [13] [14]. Currently used composite materials based on thermoset as well as thermoplastics include sheet molding compounds or bulk molding compounds (SMCs/BMCs), glass fiber mat thermoplastics (GMTs) and long fiber reinforced thermoplastic composites (LFRT), where the fiber component is glass fiber.

Other class of lightweighting materials used in automotives for the "greening" of automotive industry are natural fiber reinforced composites. Replacement of glass fibers with natural fibers allows lighter components as the density of natural fibers (1.5 g/cc) are lower compared to glass fibers ( $2.5 \mathrm{~g} / \mathrm{cc})$ while simultaneously increasing the proportion of renewable resource content within the vehicle. Many manufacturers are using these green fiber composites for non- and semi-structural applications in their vehicles and examples are given in Table 1 .

As far as the market outlook for total lightweight materials for automotive industry is concerned, its growth is expected by CAGR of $8.5 \%$ till 2019, whereas composite market will experience a growth of CAGR of $6.6 \%$, Figure 4 [16]. In another market study, the demand for lightweight materials, polymers and composites, in the North American automotive market, is projected to rise to 8020 million pounds in year 2019 which is $53 \%$ higher than year 2008 [17].

In the following sections of this article, after reviewing major OEMs' plans to implement their lightweight material development programs, a detailed discussion is presented on emerging trends in low-cost carbon fibre and cellulose-enabled composites which are projected not only to replace traditional plastic-specific automotive 


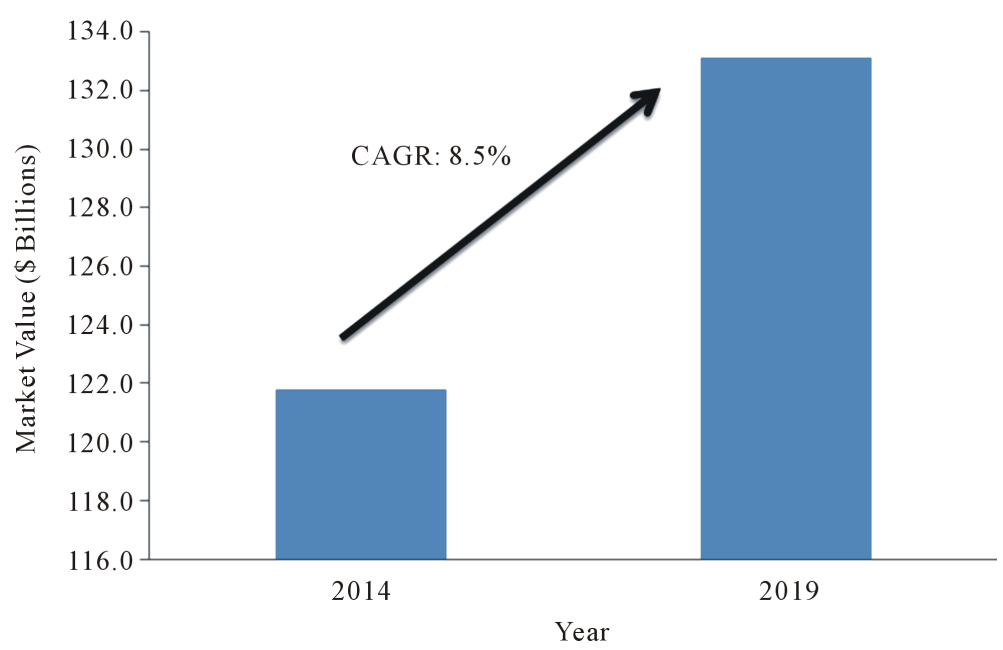

Figure 4. Global trend and forecast of lightweight materials demand.

Table 1. Applications of natural fiber composites in vehicles by different manufacturers [15].

\begin{tabular}{|c|c|c|}
\hline Manufacturer & Model & NFC composite parts \\
\hline Audi & A2, A3, A4, Avant, A6 & $\begin{array}{l}\text { Seat backs, side and back door panel, boot lining, } \\
\text { hat track, and spare tire lining }\end{array}$ \\
\hline BMW & 3,5 , and 7 series and others & $\begin{array}{l}\text { Door panels, headliner panel, noise insulation panels, } \\
\text { seat backs, molded foot and well linings }\end{array}$ \\
\hline Daimler/Chrysler & $\begin{array}{l}\text { A,C, E, and S Class } \\
\text { Evo Bus (exterior) }\end{array}$ & $\begin{array}{c}\text { Door panel, windshield, dash board, business table, } \\
\text { and pillar cover panel }\end{array}$ \\
\hline FORD & Mondeo CD 162, FOCUS & Door panles, B-Pillar, and boot liner \\
\hline Mercedes-Benz & Trucks & $\begin{array}{l}\text { Internal engine cover, engine insulation, sun visor, } \\
\text { interior insulation, bumper, wheel box and roof cover }\end{array}$ \\
\hline Toyota & Brevis, Harrier, Celsior, RAUM & Door panels, seat backs, and spare tire cover \\
\hline Volkswagen & $\begin{array}{l}\text { Golf, Passat, Variant, } \\
\text { Bora, Fox, Polo }\end{array}$ & $\begin{array}{l}\text { Door panels, seat backs, boot liner, } \\
\text { and boot lid finish panel }\end{array}$ \\
\hline Volvo & C70, V70 & Seat padding, natural foams, and cargo floor tray. \\
\hline
\end{tabular}

parts, but also have potential to substitute metallic components in a cost-effective manner.

\section{Environmental Implications: Consumer Needs \& OEMs' Proactive Action Plans}

Global climate change issues leading to catastrophic natural disasters in recent times have transformed consumer awareness and their priorities. Now these well-informed customers of automobiles place fuel efficiency and environmental friendliness design among their top four priorities, Figure 5, as reported by a recent comprehensive assessment of the global automotive industry by KPMG International [18].

By the year 2020, automotive market is expected to grow to 100 million new vehicles per year. "Lightweighting” in transport industry has become a major theme of research in recent years; the main motives being anticipated fuel savings and meeting stricter environmental legislations in various jurisdictions such as Europe, North America, and Asia. In order to meet the $\mathrm{CO}_{2}$ emission targets set for Europe in 2020, i.e., 95 g $\mathrm{CO}_{2} / \mathrm{km}$, a 200 - $300 \mathrm{~kg}$ weight reduction of the vehicle is required [19]. North American automotive OEMs are striving hard to reduce their overall fleet weight in significant numbers for both luxury and standard cars; in fact some companies have set an ambitious target of reducing up to $350 \mathrm{~kg}$ (about 20\%) of car weight by 2020 [20] as shown in Figure 6. 


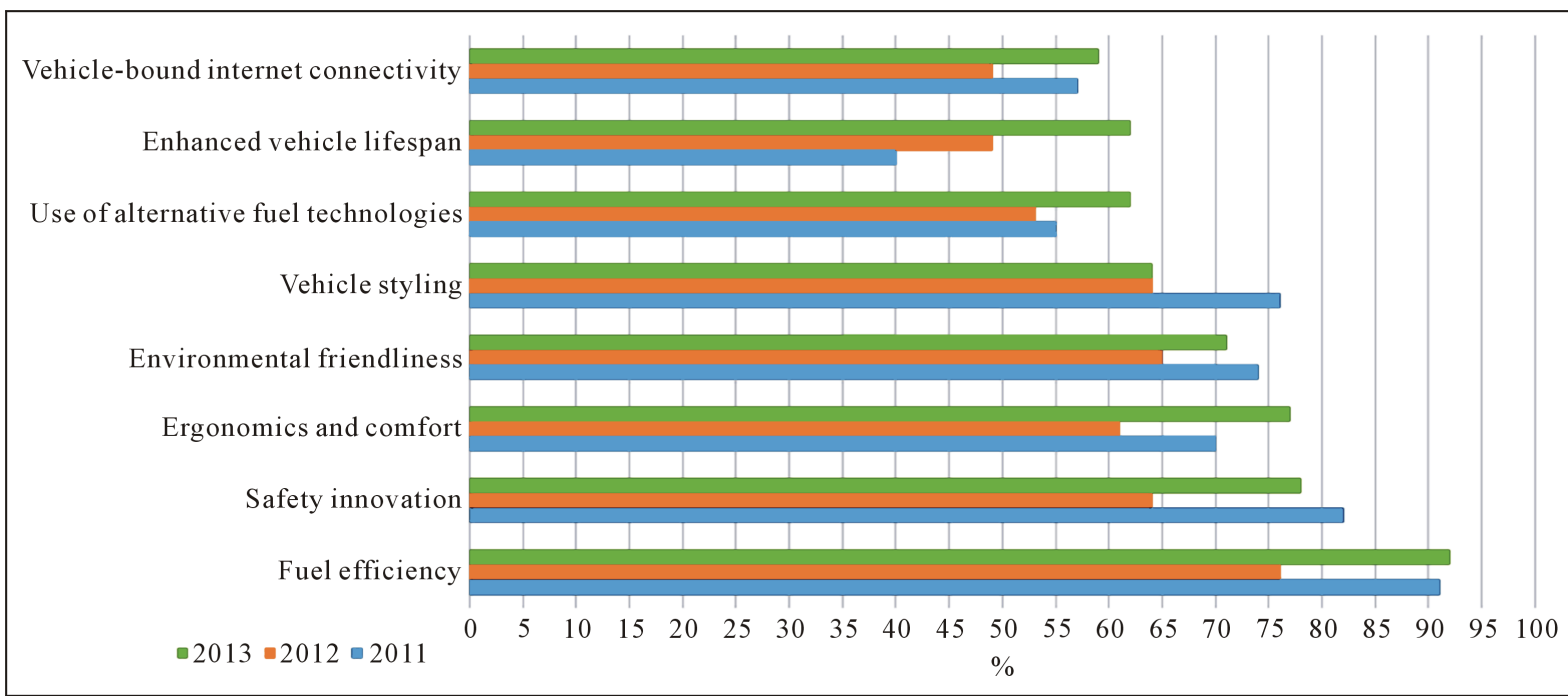

Figure 5. Automotive consumers’ top priority areas for years 2011-2013; data source [16].

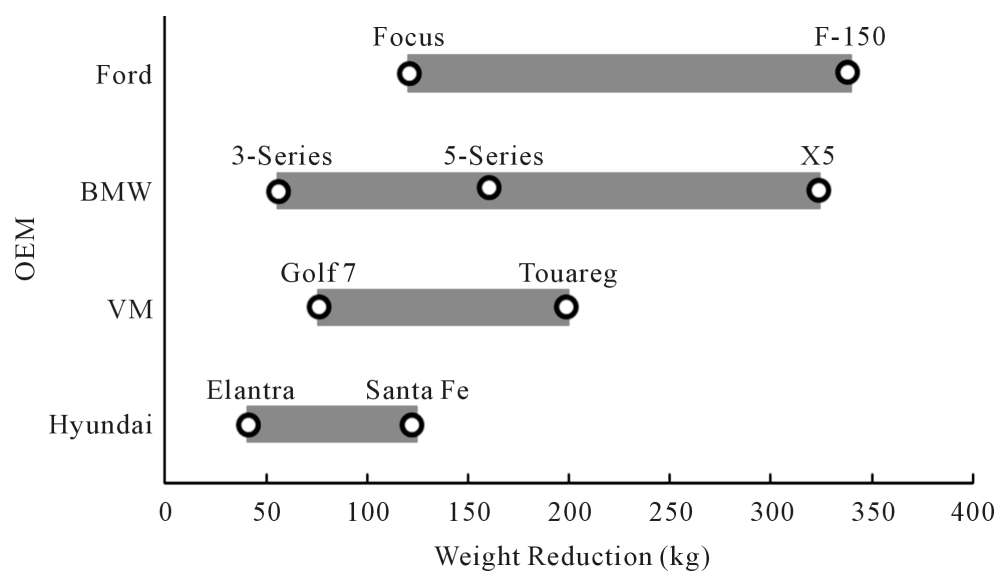

Figure 6. Auto lightweighting agenda of major global OEMs and their models from 2013 to 2020.

Overall, according to same report, 9 out of 11 automotive OEMs plan to reduce a weight of at least $100 \mathrm{Kg}$ year over year (YoY) of their entire fleet weight. The main reason cited for this accelerated weight reducing program is to meet strict North American fuel efficiency levels and $\mathrm{CO}_{2}$ emission standards in Europe. The OEMs spearheading these programs involve both mass scale producers, like Hyundai Motor, Volkswagen AG and Ford Motor and luxury vehicle manufacturers such as BMW AG and Audi AG who have been pioneers in lightweighting.

\section{Emerging Trends in the Lightweigting Material Development: Carbon Fibre-A Resurging Dream Material}

Lightweight design of automotive construction materials has become of paramount importance to not only reduce the carbon footprint of their final products but also to conserve valuable and depleting resources. The existing approaches of substitution and structure re-designing with traditional materials have reached their limits and there exists an urgent need to explore non-metallic but equally functional set of materials to achieve stricter fuel saving targets. Quite recently, lightweight fibre-reinforced plastics (FRP) have become material of choice due to their flexibility, functionality and formability into intricate hybrid and multi-part designs. Generally the FRPs are employed in areas dominated with tensile-stress, whereas metals find their utility in compressive-stress areas of automotive applications [21]. 
Recently, carbon fibers are being used as the reinforcement for plastic matrices, as these composites have most weight reduction potential, and have higher stiffness compared to glass counterparts-commercial grade carbon fibers offers a modulus of $230 \mathrm{GPa}$, which is three times higher compared to E-glass fibers (70 GPa) with a specific gravity only of $70 \%$ of E-glass fibers [22]. However, the high cost seems a hindrance to mass scale exploitation of this wonder material. Recent advances in manufacturing low-cost carbon fibre and its recycling has opened up new venues for lightweight automotive manufacturing.

\section{Emerging Trends: Carbon Fibre-Reinforced Hybrid Automotive Lightweight Materials}

Carbon fibre, being twice as strong and 30\% lighter compared to glass fibre [22] [23] has been used in automotive applications for some time. However, due to very high cost, these materials are usually employed in high-end products like sports vehicles or luxury cars. Hybrid design of carbon and glass fibre reinforced composites have been recently introduced with encouraging results. Hybrid composite structures have been developed using varying ratio of glass and carbon woven fabric in epoxy matrices and it is shown that, when employing at the exterior, composite laminates having $50 \%$ ratio of carbon fibre reinforcement exhibits optimum flexural properties and alternating carbon/glass lay-up arrangement ensures best compressive strength [24].

Commercial products arising from research in this area has already been developed by a number of companies. Quantum Composites (Bay City, Mich., USA), a subsidiary of The Composites Group, has very recently launched a hybrid carbon-glass fiber composite material, believed to be a high-strength, cost effective and lightweight substitute for conventional metal and glass fibre applications in the automotive industry. This brand named hybrid material, AMC-8590-12CFH, is suitable for fast-cure compression molding to manufacture complex parts on mass-scale [25] [26].

Very recently, Department of Energy USA in association with various universities and research institutes has launched the Institute for Advanced Composites Manufacturing Innovation (IACMI); the University of Tennessee, Knoxville, and Oak Ridge National Laboratory being founding research partners. Funded through $\$ 70$ million in federal and \$180 million in non-federal funds, IACMI will focus on increasing production capacity of carbon fibre and developing less expensive but advanced fiber-reinforced polymer composites for automotive and other industrial sectors [27]. Incorporating short and nano fibres can certainly exploit the fullest potential of high strength carbon material in hybrid design as a measure to have better properties and economize the formulation. Fua et al. [23] have reported 20\% increase in ultimate tensile strength of short carbon fibre-polypropylene composites compared to similar glass fibre-filled samples. Although synthesis of nano carbon fibre and their composites have been reported highly energy intensive, up to 12 times more energy consuming compared to steel, but overall life cycle studies have shown net savings in energy due to lightweight body parts used in vehicles [28]. Hybrid formulations, where carbon fibre is selectively incorporated into glass or other reinforcement fibres to enhance performance along lading paths in automotive applications, is one option to offset high cost of carbon fibres. However, a true potential of this otherwise excellent lightweight material can be realized until economically sustainable manufacturing methods are not introduced. Currently, research institutes and other stake holders are actively working on three research themes;

- Advanced/alternate production techniques to produce low-cost carbon fibre from traditional feedstock, like PAN precursor.

- Exploring low cost and renewable pre-cursors to synthesis carbon fibres.

- Recycling of carbon fibre in large volumes.

\section{Low-Cost Carbon Economy}

\subsection{Advanced Production Techniques and Alternate "Affordable" Feedstock}

The manufacturing cost of carbon fiber is the main deciding factor in its ultimate use in lightweight automotive industry on mass scale; around 50\% manufacturing cost being attributed to precursor feedstock whereas $43 \%$ refers to conversion process in transforming precursor into carbon fibre and surface treatment, rest being spent on spooling, etc. [29]. A number of research efforts are underway to develop low-cost conversion techniques in reducing overall cost of carbon fibre from traditional precursor, PAN. Oak Ridge National Laboratory (ORNL), USA, has been working to develop a higher-speed, lower-cost oxidative stabilization process and very recently, in collaboration with RMX Technologies (RMX), they have scaled up a plasma-based oxidation process to the 
capacity of 1 ton/year. ONRL has further reported a net savings of 30\% in energy consumption per kg of carbon fibre compared to conventional methods [7] [30].

\subsection{Affordable Feedstock}

A number of alternate options for affordable precursor feedstock are now available; however significant research work is required to commercialize manufacturing methods. Currently, most widely explored feedstock are; lignin based precursor (both hardwood/softwood), textile grade PAN (MA or VA formulations), and polyolefins.

Center for Biocomposites and Biomaterials Processing (CBBP), University of Toronto, Canada has done considerable research in using renewable sources for value added products [31]-[34]. In a recent study lignin fibers were developed through melt spinning from a commercial available soda hardwood lignin (SHL) while using poly (ethylene oxide) as a plasticizer. After determining the guaiacyl/syringyl ratio in SHL, a suitable temperature profile for the melt spinning was predicted through rheological studies [35]. Thunga et al. [36] have investigated lignin as a suitable precursor for carbon fibers; lignin was chemically modified and blended with poly (lactic acid) (PLA) biopolymer before melt spinning into lignin fibers. In another research work, an economically viable and technologically sound process for the production of low-cost carbon fibers made of lignin copolymer with acrylonitrile (AN) is also reported where lignin was copolymerized with AN in dimethysulfoxide (DMSO) [37]. Zolteck Companies Inc and DOE, USA have jointly developed lignin/PAN carbon fibres, Figure 7 [7]. The main objective of this project was to develop and commercially validate a low cost carbon fiber, $\sim \$ 5.00 / \mathrm{lb}$, having desired properties of strength; 250,000 psi, modulus of elasticity; 25,000,000 psi, and strainto-failure; >1\%. The commercial validation of this project is scheduled to be completed by year 2015.

\subsection{Recycling of Carbon Fibre}

Widespread landfilling of solid waste around global urban centres have prompted the need of recycling to new levels [38]. As the automotive lightweighting mandate is gaining momentum rapidly, concerned OEMs are looking forward to cost-effective feedstock options to develop composite structures. Although the automotive industry sector was using only 2150 tonnes, about 5\%, of total global carbon fibre use in year 2012, however, there exists a great potential of growth in this industry. According to a recent market study, published by Carbon Composites eV and AVK, the annual growth of carbon fibre in the automotive sector is predicted around 34\% by year 2020, ranking among top three carbon fiber consuming market [39]. Recycling of carbon fibre has seen great urgency in recent times among not only virgin fibre manufacturers but also post-consumer material handlers. Another very critical motive for recycling of carbon fibre is the compliance with the European Union (EU) end-of-life-vehicle (ELV) directive which dictates that 85 percent, by weight, of the materials used in automotives, especially car and light truck built for the 2015 model year and beyond, must be recyclable [40].
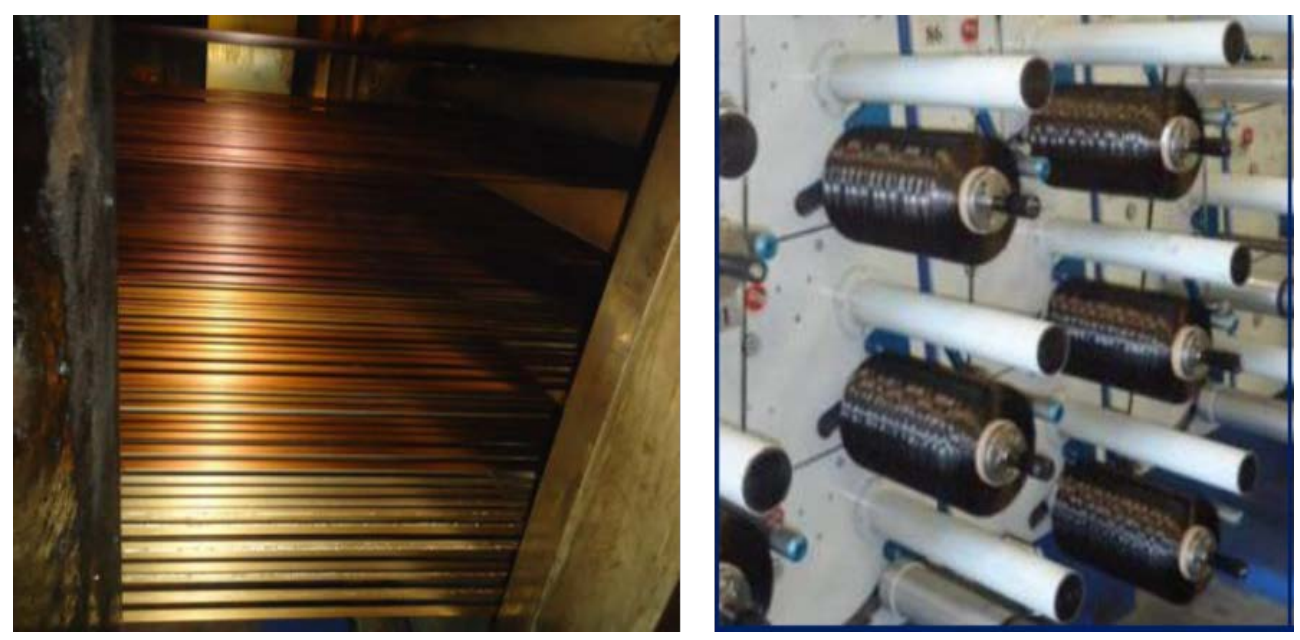

Figure 7. Lignin/PAN carbon fibres produced under joint project of Zolteck Companies Inc and DOE, USA; with permisssion from DOE-USA. 
Responding to ever increasing demand of carbon fibre, Figure 8, a number of commercial organizations have setup a vigorous carbon fiber recycling programs of their own, mostly in North America and EU. Use and recycling of carbon fibre has become such an important strategic issue that a bill has been introduced in US Senate requesting a study of the technology and energy savings of recycled carbon fiber. The bill, S. 1432, the Carbon Fiber Recycling Act of 2015, also directs the DOE to collaborate with the automotive and aviation industry to develop a recycled carbon fiber demonstration project [41]. Some of the noteworthy initiatives are;

- SGL-Germany: A BMW-SGL joint venture, SGL Automotive Carbon Fibers, has developed a recycling process to recirculate carbon fibers into the production process. A new material class "Recycled carbon fibers RECAFIL" has been introduced in the form of a Carbon Fiber Cut Mix or as so-called Carbon Fiber Flocks. SGL recycles CF scrap from weaving into non-woven mats and subsequently molds these materials into rear seat and roof structures of BMW i3 models, Figure 9 [40] [42] [43].

- CFK Valley Recycling (Stade, Germany) is another major player in reclaiming carbon fibre, particularly from aerospace industry. The fiber reclaimed by current means is chopped and not suitable for use in wind turbine and aircraft structures. However, discontinuous fiber has long been a favorite of automotive composites, especially interiors and under the hood applications.

- MIT-LLC, USA, started reclaiming carbon fibres 2009 from different industrial waste streams through its own indigenous processes. The reclaimed carbon fibres are transformed into wet-laid nonwoven preforms measuring in widths up to 49 inch and weighing 50 to $1000 \mathrm{~g} / \mathrm{m}^{2}$. MIT uses its Three Dimensional Engineered Preform (3-DEP ${ }^{\circledR}$ ) chopped fiber composite technology, developed under DOE-USA Small Business Innovation Research (SBIR) project, to address the need for cost-effective, high volume, lighter weight components for automobiles.

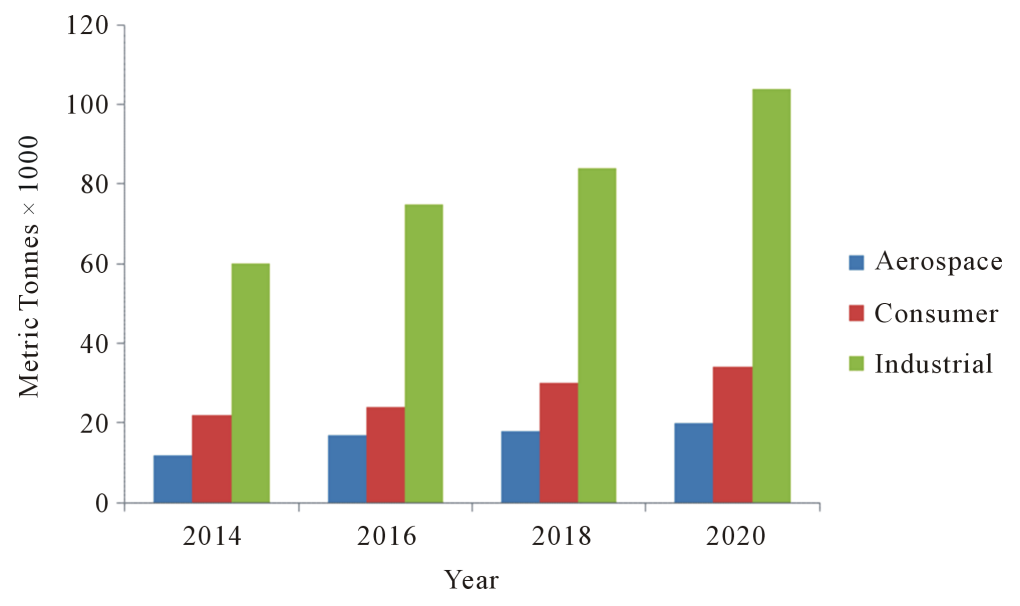

Figure 8. Global carbon fibre production by market; 2012-2020; data source [40].

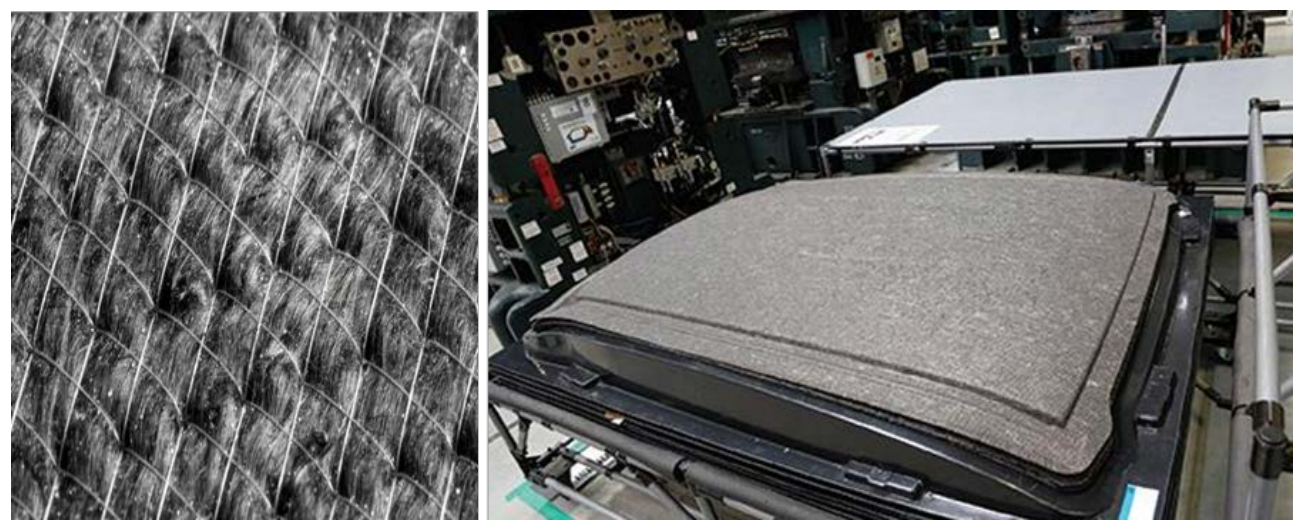

Figure 9. Non-woven mats from recycled carbon fibers transformed into BMW i-series CFRP Life Module roof structure; with permission from [42]. 


\section{Cellulose-Enabled Hybrid Lightweight Engineered Composites}

CBBP has demonstrated an economically and technically feasible innovative Microfiber technology (MF technology) to manufacture cellulose microfiber-enabled composite materials from a variety of biomass feed stocks [44] [45]. Using this technology, the short yet high aspect ratio biofibres are microfibrilled and well-dispersed in the polymer matrix, thus manufacturing a new high performing microfibre-composite a within very short cycle times. Table 2 shows the comparison of the composites with the $40 \%$ glass fiber reinforced composites. Although MF-technology leads to high performance composites, the poor impact performance of the composites restricts their use in high-end applications.

In order to enhance the impact performance of the micro-fiber composites, this microfibre technology (MF) has been integrated with the currently used Direct-Long Fibre Thermoplastic technology (DLFT), which is the current method for manufacturing long fibre composites economically, and have developed Micro Fibre DirectLong Fibre Thermoplastic technology, MF-DLFT. We have demonstrated this technology, in association with the industrial partners, to manufacture with greater performing hybrid composites-cellulose micro fiber and carbon fiber reinforced hybrid composites-for automotive under the hood applications. OEM requirement of the two under the hood parts are given in the Table 3.

Microfibre-enabled composites have several unique advantages compared to conventional glass-filled thermoplastic structures; being 15\% - 30\% lightweight being the most important one, and can lead to about 14\% of fuel economy. With the developed technology CBBP has developed various cellulose micro-fiber carbon fiber hybrid composites intending to use for various applications, and the details are given in the Table 4 along with the cost of the materials.

Table 2. Comparison of the mechanical performance of the composites prepared as per the modified MF technology with that of $40 \%$ glass fiber reinforced polypropylene.

\begin{tabular}{ccc}
\hline Performance property & $40 \%$ GF reinforced $\mathrm{PP}^{*}$ & $\begin{array}{c}\text { MF-technology plus short glass } \\
\text { fibre hybrid [46] }\end{array}$ \\
\hline Fibre content (wt\%) & 40 & 50 \\
Tensile strength, MPa & 101 & $\sim 90$ \\
Flexural strength, MPa & 160 & $\sim 135$ \\
Flexural modulus, GPa & 6.2 & $\sim 6.5$ \\
Izod impact strength, J/m & 214 & - \\
Density $\left(\mathrm{g} / \mathrm{cm}^{3}\right.$ ) & 1.14 & 1.10 \\
\hline
\end{tabular}

* Data from the samples prepared in our lab using $40 \%$ GF filled composites provided by industry partners.

Table 3. Comparison of the properties of the cellulose microfiber hybrid composites with the OEM specifications.

\begin{tabular}{cccc}
\hline Property specification & Engine cover & Cam cover & $\begin{array}{c}\text { CBBP MF-DLFT } \\
\text { hybrid composite }\end{array}$ \\
\hline Tensile strength, MPa & 110 & 85 & $=,+$ \\
Flexural modulus, GPa & 7.1 & 7.2 & $=,+$ \\
Impact strength @23 ${ }^{\circ} \mathrm{C}, \mathrm{kJ} / \mathrm{m}^{2}$ & 3.1 & 4 & $\sim$ \\
HDT @1.82 MPa, ${ }^{\circ} \mathrm{C}$ & 187 & 170 & - \\
Flammability, $(\mathrm{mm} / \mathrm{min})$ & $<100 \mathrm{~mm} / \mathrm{min}$ & $<100 \mathrm{~mm} / \mathrm{min}$ & + \\
Density, g/cm & $1.32-1.42$ & 1.47 & + \\
Current materials & $30 \%$ glass filled PA6 & $40 \%$ glass filled PA66 & $\begin{array}{c}\text { Cellulose microfiber + } \\
\text { carbon fiber reinforced PP }\end{array}$
\end{tabular}

*= equal; + exceeds; about the same; ++ exceeds well above. 
Various under the hood parts were successfully prototyped in association with one of our industrial partners, FORD Canada, and few of the parts are shown in the Figure 10. Life cycle analysis of these composite materials are underway and the results will be published soon. Our study on the LCA of engine cover showed that $30 \%$ of weight reduction of a part in the vehicle body can reduce about $21 \mathrm{~kg}$ of $\mathrm{CO}_{2}$ emission for the vehicle's lifespan.

Currently, our research is focused on the development of high performing lightweight automotive prototypes using cellulosic nanocellulose composites as these fibers have significantly higher strength and stiffness compared to the natural fibers and micro fibers. Other companies and researchers are also moving to this direction. Recently, two companies, (American Process Inc., Atlanta, GA and Futuris Automotive, Melbourne, Australia) formed a partnership with researchers at three different research institutions (Georgia Institute of Technology, Clark Atlanta University, Swinburne University of Technology, and the USDA's Forest Products Laboratory) for developing ultra-strong and lightweight automotive structural components using nanocellulose reinforced composites [47]. This particular partnership's goal is to use the advanced reinforced polymers in cars to replace heavy steel structures within cars, such as the seat frames, that can compete with the cost of traditional materials. In the future, nanocellulose composites seems to an economical substitute for expensive light-weight carbon fiber composites currently used in some luxury automobiles such as BMW's all-electric i3.

Table 4. Details of the hybrid composites prepared at the CBBP center and the percentage weight reduction compared to the currently being used composite materials in the automotive applications.

\begin{tabular}{|c|c|c|c|c|c|c|}
\hline $\begin{array}{c}\text { CBBP MF } \\
\text { composite name }\end{array}$ & Generic name & $\begin{array}{c}\text { Renewable } \\
\text { content (wt\%) }\end{array}$ & Intended application & $\begin{array}{c}\text { Cost/lb* } \\
\text { (US\$) }\end{array}$ & $\begin{array}{l}\text { Prototype } \\
\text { build to-date }\end{array}$ & $\begin{array}{l}\text { Weight } \\
\text { reduction (\%) }\end{array}$ \\
\hline MiCelD210-PP & $\begin{array}{c}\text { Cellulose hybrid fiber } \\
\text { polypropylene composite }\end{array}$ & $20-30$ & $\begin{array}{c}\text { Engine cover, extension panel } \\
\text { dash, battery tray, door carrier } \\
\text { plates, air inlet box }\end{array}$ & 1.31 & Engine cover & 30 \\
\hline MiCelD215-PP & $\begin{array}{c}\text { Cellulose hybrid fiber } \\
\text { polypropylene composite }\end{array}$ & $20-35$ & $\begin{array}{l}\text { Oil pan, cam cover, windage } \\
\text { tray, engine front cover, } \\
\text { intake manifold }\end{array}$ & 1.39 & $\begin{array}{l}\text { Oil pan, } \\
\text { cam cover }\end{array}$ & 20 \\
\hline MiCelD112-PP & $\begin{array}{l}\text { Cellulose hybrid fiber } \\
\text { polypropylene composite }\end{array}$ & 20 & $\begin{array}{c}\text { Engine cover, extension panel } \\
\text { dash, battery tray, door carrier } \\
\text { plates, air inlet box }\end{array}$ & 1.43 & Battery tray & 25 \\
\hline MiCelE000-PP & $\begin{array}{c}\text { Cellulose fiber } \\
\text { polypropylene composite }\end{array}$ & 25 & $\begin{array}{c}\text { Interior parts with } \\
\text { glass/mineral filled PP }\end{array}$ & 1.17 & Door cladding & 15 \\
\hline
\end{tabular}

* Cost is calculated based on the price of the small scale shipment of raw materials and will be further reduced in the real scenario.

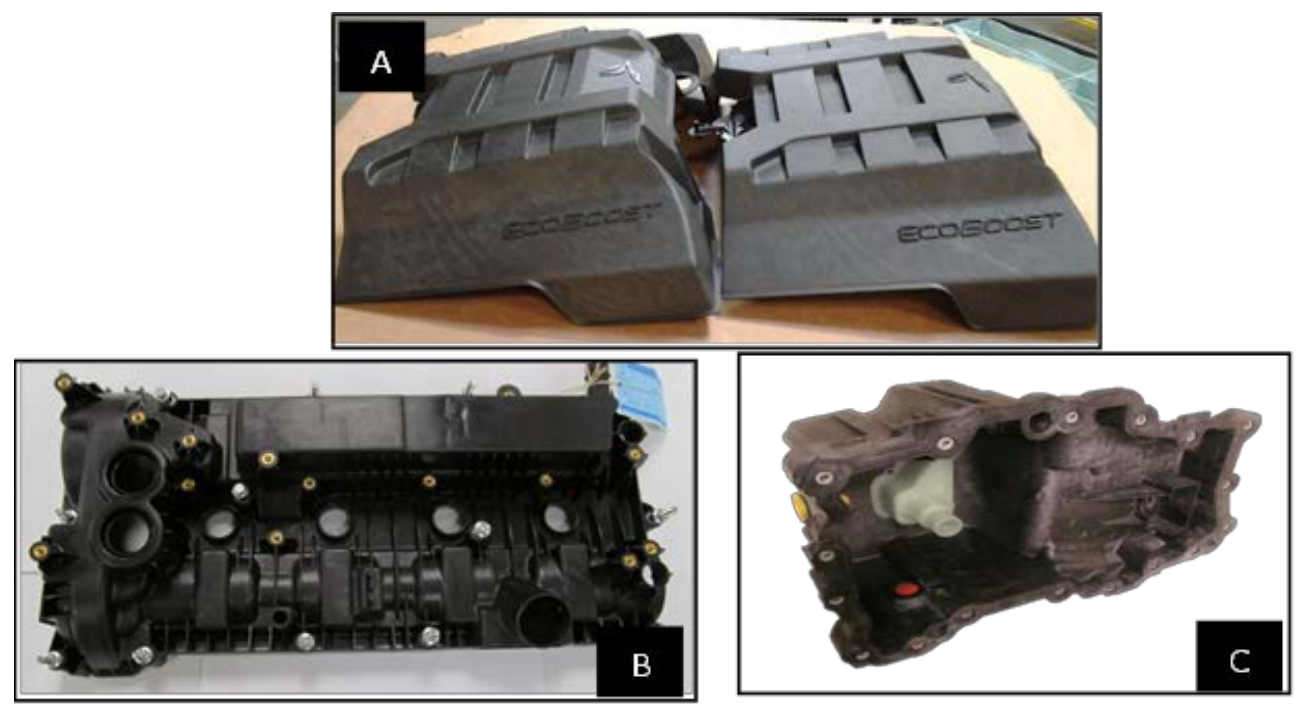

Figure 10. Prototypes of engine cover (A), cam cover (B), and oil pan (C) developed by CBBP, University of Toronto, Canada. 


\section{Conclusions}

Recent climate change scenario associated with drastic natural disasters has prompted an urgent need to global community in mitigating GHG emissions on realistic and war-footing basis. Road transport, using substantial amounts of fossil fuel for its energy requirements, accounts for almost one third of all GHG related emissions worldwide. In these circumstances, automotive fuel economy, achieved through lightweight construction materials, becomes a single most important factor to not only combat $\mathrm{CO}_{2}$ emissions on large scale but also provide energy security on regional basis. European Union and North America in particular have formulated comprehensive agendas in developing lightweight automotive materials leading to stringent fuel economy standards in coming years.

Apart from lightweight metallic alloys and multi-material design options, emerging trends in fibre-based hybrid composite structures provide a different kind of viable solution in the development of lightweight vehicles. Recent technological advances in the utilization of cellulose and carbon fibre-enabled composite formulations have led to revolutionize the design of not only standard but also luxury vehicles. Essentially speaking, use of renewably-sourced cellulose fibre in advanced composite materials has already passed the proof-of-concept phase and, after achieving technical validation, is now ready for scale-up commercial opportunities. CBBP, a university of Toronto center of excellence in association with automotive industrial partners, has demonstrated a practical feasibility of designing $20 \%-30 \%$ lightweight hybrid prototypes which are currently under further validation studies before going to commercial applications. Further, availability of low-cost carbon fibre in near future, due to intense competition in recycling on large scale, will enable more feasible routes in the development of hybrid lightweight automotive materials. This will certainly facilitate significantly in achieving fuel economy of 50+ MPG $(20+\mathrm{kpl})$ for most of vehicles in coming decade, as required by major environmental protection agencies.

\section{Acknowledgements}

This work was supported financially by the NSERC, Canada, under Automotive Partnership Canada (APC) program; NSERC-APC Grant No: APCPJ 433821-12. Authors would also like to thank Ford Motor Company, Canada, for their in-kind support.

\section{References}

[1] Hill, K., Menk, D. and Cregger, J. (2015) Contribution of the Automotive Industry to the Economies of All Fifty States and the United States. Center for Automotive Research, Alliance of Automobile Manufacturers Washington DC.

[2] EPA (2013) Transportation Sector Emissions; Emissions and Trends. http://www.epa.gov/climatechange/ghgemissions/sources/transportation.html

[3] Boden, T.A., Marland, G. and Andres, R.G. (2010) Global, Regional, and National Fossil-Fuel $\mathrm{CO}_{2}$ Emissions. Carbon Dioxide Information Analysis Center, Oak Ridge National Laboratory, U.S. Department of Energy, Oak Ridge. http://dx.doi.org/10.3334/cdiac/00001 v2010

[4] White House Fact Sheet (2014) Office of the Press Secretary. U.S.-China Joint Announcement on Climate Change and Clean Energy Cooperation.

https://www.whitehouse.gov/the-press-office/2014/11/11/fact-sheet-us-china-joint-announcement-climate-change-andclean-energy-c

[5] EPA (2015) Proposed Rulemaking: Phase 2 Greenhouse Gas Emissions Standards and Fuel Efficiency Standards for Medium- and Heavy-Duty Engines and Vehicles. http://www.epa.gov/otaq/climate/regs-heavy-duty.htm

[6] WH.Gov. (2014) Kicking Vehicle Efficiency into High Gear. The White House Blog. https://www.whitehouse.gov/blog/2014/02/18/kicking-vehicle-efficiency-high-gear

[7] DOE, VTO (2013) Vehicle Technologies Office: Lightweight Materials R\&D Annual Progress Report. http://energy.gov/eere/vehicles/downloads/vehicle-technologies-office-2013-lightweight-materials-rd-annual-progress

[8] Cheah, L.W. (2010) Cars on a Diet: The Material and Energy Impacts of Passenger Vehicle Weight Reduction in the U.S. PhD Thesis, The Engineering Systems Division, Massachusetts Institute of Technology.

[9] DOE, VTO (2015) Vehicle Technologies Office: Materials Technologies. Office of Energy Efficiency \& Renewable Energy. http://energy.gov/eere/vehicles/vehicle-technologies-office-materials-technologies

[10] NIST (2014) Energy Advantages of Shedding Weight. Center for Automotive Lightweighting. http://www.nist.gov/lightweighting/ncalfeature.cfm 
[11] Geck, P.E. (2014) Automotive Lightweighting Using Advanced High-Strength Steels. SAE International, Warrendale. http://dx.doi.org/10.4271/r-431

[12] Das, S. (2011) Life Cycle Assessment of Carbon Fiber-Reinforced Polymer Composites. The International Journal of Life Cycle Assessment, 16, 268-282. http://dx.doi.org/10.1007/s11367-011-0264-z

[13] Car Makers Increase Their Use of Composites. Reinforced Plastics, February 2004. www.reinforcedplastics.com

[14] Lightweighting the Automotive Market. Reinforced Plastics, February/March 2009. www.reinforcedplastics.com

[15] Ahmad, F., Choi, H.S. and Park, M.K. (2015) A Review: Natural Fiber Composites Selection in View of Mechanical, Light Weight, and Economic Properties. Macromolecular Materials and Engineering, 300, 10-24. http://dx.doi.org/10.1002/mame.201400089

[16] Markets and Markets (2014) Lightweight Materials Market by Type (Composites, Metals, Plastics), Application (Automotive, Aviation, Marine, Wind Energy)—Global Trends \& Forecast to 2019. Report Buyer, UK.

[17] Holmes, M. (2014) Demand for Lightweight Automotive Materials in North America to Continue to Rise. Reinforced Plastics News, June 2014. http://www.materialstoday.com/composite-applications/news/demand-for-lightweight-automotive-materials-in/

[18] KPMG (2013) KPMG’s Global Automotive Executive Survey, Pub No. 121249.

[19] Composite Developments Drive Auto Industry Forward. Reinforced Plastics, May/June 2014. www.reinforcedplastics.com

[20] Shankar, V. (2013) Global Automotive OEMs Embrace Lightweighting to Attain Fuel Economy and Emission Goals. Frost \& Sullivan Market Report. http://www.frost.com/sublib/display-market-insight.do?id=279328612\&ctxixpLink=FcmCtx1\&ctxixpLabel=FcmCtx2

[21] Nehuis, F., Kleemann, S. and Egede, P. (2014) Future Trends in the Development of Vehicle Bodies Regarding Lightweight and Cost. In: Bajpai, R.P., et al., Eds., Innovative Design, Analysis and Development Practices in Aerospace and Automotive Engineering, Springer, New Delhi, 13-21. http://dx.doi.org/10.1007/978-81-322-1871-5_3

[22] Brookbank, P., Savage, L. and Evans, K.E. (2015) Economical Carbon and Cellulosic Sheet Moulding Compounds for Semi- and Non-Structural Applications. Journal of Reinforced Plastics and Composites, 34, 437-453. http://dx.doi.org/10.1177/0731684415572437

[23] Fua, S.Y., Laukeb, B. and Maderb, E. (2000) Tensile Properties of Short-Glass-Fiber- and Short-Carbon-Fiber-Reinforced Polypropylene Composites. Composites: Part A, 31, 1117-1125. http://dx.doi.org/10.1016/S1359-835X(00)00068-3

[24] Zhang, J., Chaisombat, K. and He, S. (2012) Hybrid Composite Laminates Reinforced with Glass/Carbon Woven Fabrics for Lightweight Load Bearing Structures. Materials and Design, 36, 75-80. http://dx.doi.org/10.1016/j.matdes.2011.11.006

[25] Composites World. Hybrid Carbon Fiber/Glass Fiber Reinforcement. Posted on 17 Feb, 2014. http://www.compositesworld.com/products/hybrid-carbon-fiberglass-fiber-reinforcement

[26] Quantum Composites. Quantum Composites Launches First Hybrid Carbon Fiber Material. Feb. 2014. http://www.quantumcomposites.com/

[27] Sloan, J. (2015) IACMI Consortium Formally Launched in Tennessee. Industry News; Composites World, Posted 22 June, 2015. http://www.compositesworld.com/news/iacmi-consortium-formally-launched-in-tennessee

[28] Khanna, V. and Bakshi, B. (2009) Carbon Nanofiber Polymer Composites: Evaluation of Life Cycle Energy Use. Environmental Science \& Technology, 43, 2078-2084. http://dx.doi.org/10.1021/es802101x

[29] Friedfeld, B. (2007) Cost Assessment of Lignin- and PAN-Based Precursor for Low-Cost Carbon Fiber. Presentation for the Automotive Composites Consortium, 17 January 2007.

[30] US Drive (2015) Highlights of Technical Accomplishments 2014; Overview. http://energy.gov/sites/prod/files/2015/04/f21/2014\%20U.S.\%20DRIVE\%20Accomplishments\%20Report.pdf

[31] Birat, K.C., Panthapulakkal, S., Kronka, A., Agnelli, J.A.M., Tjong, J. and Sain, M. (2015) Hybrid Biocomposites with Enhanced Thermal and Mechanical Properties for Structural Applications. Journal of Applied Polymer Science, 132. http://dx.doi.org/10.1002/app.42452

[32] Panthapulakkal, S., Law, S. and Sain, M. (2006) Performance of Injection Molded Natural Fiber-Hybrid Thermoplastic Composites for Automotive Structural Applications. SAE Technical Paper 2006-01-0004. http://dx.doi.org/10.4271/2006-01-0004

[33] Pervaiz, M. and Sain, M. (2004) High Performance Natural Fiber Thermoplastics for Automotive Interior Parts. Proceedings of the SAE 2004 World Congress \& Exhibition, Detroit, 8-11 March 2004, SAE Technical Report No. 200401-0729. http://dx.doi.org/10.4271/2004-01-0729

[34] Pervaiz, M., Oakley, P. and Sain, M. (2014) Development of Novel Wax-Enabled Thermoplastic Starch Blends and 
Their Morphological, Thermal and Environmental Properties. International Journal of Composite Materials, 4, 204212.

[35] Awal, A. and Sain, M. (2013) Characterization of Soda Hardwood Lignin and the Formation of Lignin Fibers by Melt Spinning. Journal of Applied Polymer Science, 129, 2765-2771. http://dx.doi.org/10.1002/app.38911

[36] Thunga, M., Chen, K. and Grewell, D. (2014) Bio-Renewable Precursor Fibers from Lignin/Polylactide Blends for Conversion to Carbon Fibers. Carbon, 68, 159-166. http://dx.doi.org/10.1016/j.carbon.2013.10.075

[37] Maradur, S.P., Kimb, C.H. and Kimb, S.Y. (2012) Preparation of Carbon Fibers from a Lignin Copolymer with Polyacrylonitrile. Synthetic Metals, 162, 453-459. http://dx.doi.org/10.1016/j.synthmet.2012.01.017

[38] Pervaiz, M. and Sain, M. (2015) Recycling of Paper Mill Biosolids: A Review on Current Practices and Emerging Biorefinery Initiatives. CLEAN—Soil, Air, Water, 43, 919-926. http://dx.doi.org/10.1002/clen.201400590

[39] Carbon Fibre and Cars-2013 in Review. Reinforced Plastics January 2014. http://www.materialstoday.com/carbon-fiber/features/carbon-fibre-and-cars-2013-in-review/

[40] Gardiner, G. (2014) Recycled Carbon Fiber Update: Closing the CFRP Lifecycle Loop. Composites World, 30 November 2014. http://www.compositesworld.com/articles/recycled-carbon-fiber-update-closing-the-cfrp-lifecycle-loop

[41] Caliendo, H. (2015) New Bill Requests Study on Carbon Fiber Recycling. Industry News, Composites World, 22 June 2015. http://www.compositesworld.com/news/new-bill-requests-study-on-carbon-fiber-recycling-

[42] BMW Press Club Global (2015) https://www.press.bmwgroup.com/global/startpage.html.

[43] SGL. RECAFIL ${ }^{\circledR}$ Recycled Carbon Fibers. https://www.sglgroup.com/cms/international/products/product-groups/cf/recafil/index.html?_locale=en

[44] Sain, M., Panthapulakkal, S. and Law, S. (2014) Manufacturing Process for High Performance Short Lingo-Cellulsoic Fiber Thermoplastic Composite Materials. US Patent 8,852,488.

[45] Sain, M., Panthapulakkal, S. and Law, S. (2014) Manufacturing Process for High Performance Lignocellulosic Fibre Composite Materials. Canadian Patent CA 2527325.

[46] Mohini, S., Panthapulakkal, S. and Law, S. (2014) Manufacturing Process for Hybrid Organic and Inorganic Fibre Filled Composite Materials. US Patent 8,940,132; Canadian Patent CA 250349.

[47] E-News Letter (2014) American Process Inc. Announces Partnership to Develop Ultra-Strong, Lightweight Automotive Components Using Nanocellulose. http://www.tappi.org/content/enewsletters/ahead/2014/issues/2014-11-26.html 